\title{
Linfoma no Hodgkin de presentación ósea. Reporte de un caso.
}

\author{
Bone non-Hodgkin lymphoma. A case report. \\ Germán Málaga ${ }^{1,4}$, Estela Mogrovejo², Enma Marín², Jaime Cáceres³
}

\section{RESUMEN}

Se describe el caso de un varón de 15 años con cuadro clínico caracterizado por dolor y aumento de volumen de la rodilla derecha, fiebre, diaforesis, cefalea, ganglios palpables y pérdida de peso. En la radiografía y RMN de rodilla se encontró acentuada alteración de la epífisis y metáfisis proximal de la tibia y de la metáfisis distal del fémur. La biopsia e inmunohistoquímica fueron compatibles con linfoma no-Hodgkin difuso de células grandes B.

PALABRAS CLAVE: Linfoma no-Hodgkin, huesos, Linfoma de Células B Grandes Difuso. (Fuente: DeCS, BIREME)

\section{SUMMARY}

We report a 15-year-old male patient who presented with pain and edema on the right knee, fever, diaphoresis, headache, palpable lymph nodes and weight loss. Marked alteration of the epiphysis and proximal metaphysis of the tibia, and of the distal metaphysis of the femur were observed in the plain x-ray and MRI images. Biopsy and immunohistochemistry findings were compatible with diffuse large B-cell non-Hodgkin lymphoma.

KEY WORDS: Lymphoma, Non-Hodgkin, bone and bones, Diffuse, Large B-Cell. (Source: MeSH NLM)

\section{INTRODUCCIÓN}

La presentación ósea como sitio primario del linfoma no-Hodgkin (LNH) es inusual. Existen pocos reportes a nivel mundial y no hemos encontrado reportes previos en nuestro medio (1-4). Presentamos un caso de LNH con afectación primaria de la tibia y el fémur.

\section{Caso clínico}

Varón deportista de alto rendimiento (basketbolista) de 15 años, natural de Venezuela, procedente de Lima, quien desde seis meses antes del ingreso presentó dolor y aumento del volumen de rodilla derecha y fiebre vespertina, acudió a un establecimiento de Salud donde se le prescribió Cefadroxilo 500mg c/12

1 Médico Internista Asistente del Hospital Nacional Cayetano Heredia. Profesor Asociado de la Facultad de Me dicina Alberto Hurtado, Universidad Peruana Cayetano Heredia. Lima, Perú.

2 Médico Cirujano. Egresado de la Facultad de Medicina Alberto Hurtado, Universidad Peruana Cayetano Here dia. Lima, Perú.

3 Médico Patólogo. Departamento de Patología, Hospital Nacional Cayetano Heredia. Lima, Perú.

4 Conocimiento y Evidencia (CONEVID). Facultad de Medicina Alberto Hurtado, Universidad Peruana Cayetano Heredia. Lima, Perú. 
horas por 7 días, con mejoría parcial. Tres meses antes del ingreso, el dolor de rodilla aumentó, agregándose hiporexia, náuseas y diaforesis. Le solicitaron una resonancia magnética nuclear (RMN) de rodilla, y se le diagnosticó "osteomielitis", recibiendo cefadroxilo $500 \mathrm{mg} \mathrm{c} / 12$ horas por 8 días adicionales sin mejoría. Dos meses antes de la admisión, se agregó aumento de volumen de "ganglios" inguinales, los que eran dolorosos. Dos semanas antes del ingreso, se añadió cefalea, aumento de volumen de ganglios cervicales y preauricular derecho, y pérdida de peso. Acudió al hospital, quedando hospitalizado.

Antecedentes: Mononucleosis infecciosa en 2008 y Herpes zoster facial en 2009. Contacto TBC (+). Abuelo "leucemia".

El examen físico mostró: PA: 110/70mmHg. FC: 100/min. FR: $22 / \mathrm{min} . \mathrm{T}: 38,5^{\circ} \mathrm{C}$. Talla: $2 \mathrm{~m}$. Peso: $70 \mathrm{~kg}$, adelgazado, marcha claudicante por dolor, piel pálida, ganglios palpables cervicales, supraclaviculares, axilares, inguinales, femorales y preauricular, el mayor de $3 \times 3 \mathrm{~cm}$; dolor en episodillo lateral del fémur, sacro, espina iliaca posterior y hombro izquierdo, y aumento de volumen y dolor de la bursa infra rotuliana derecha. Spam hepático de $16 \mathrm{~cm}$. El resto del examen físico fue normal.

Los exámenes de laboratorio mostraron: anemia leve, hipocalcemia, hipoproteinemia, hipoalbuminemia, y LDH, fosfatasa alcalina y VSG elevadas. La prueba de Elisa para VIH fue negativa y la radiografía de tórax y pulmones fue normal.

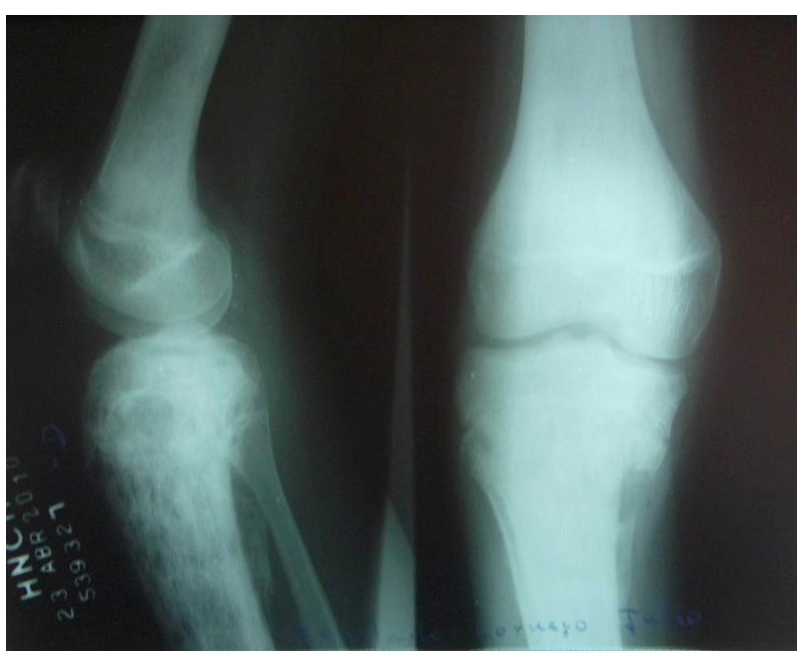

Figura 1. Radiografía de rodilla derecha, muestra una densidad heterogénea, con imágenes osteolíticas en su cara anterior.
La radiografía de rodilla derecha mostraba una densidad heterogénea, con imágenes osteolíticas en su cara anterior (Figura 1). El informe de la RMN fue "acentuada alteración de la epífisis y metáfisis proximal de la tibia, y metáfisis distal del fémur asociada a reacción perióstica en probable relación a manifestaciones de patología hematopoyética benigna o mielo/linfoproliferativa. No imágenes sugestivas de desgarro meniscal, lesión a nivel ligamentario o tendíneo" (Figuras 2, 3 y 4).

La Tomografía Axial Computarizada (TAC) de tórax, abdomen y pelvis normal.

La biopsia de ganglio femoral mostró pérdida de su arquitectura, reemplazada por proliferación neoplásica homogénea y difusa de linfocitos grandes, de núcleo vesiculoso, con nucléolo prominente y abundantes mitosis (Figura 5). Los exámenes complementarios de imunohistoquímica mostraron un perfil inmunológico compatible con Linfoma no Hodgkin difuso de células grandes B (CD20 +, CD3 -, bcl6 +/-, bcl2 -, ciclinad1-, TdT -, CD1a -, CD34 -, ki-67 alrededor del 90\%).

El aspirado de médula ósea (AMO) fue no evaluable por falta de espículas y La biopsia de hueso mostró una celularidad entre 70 a $80 \%$ con respecto al tejido adiposo, con arresto en la maduración mieloide de las 3 series, mantos de histiocitos con leve actividad fagocítica y acúmulo de linfocitos maduros.

Un mes después de finalizar la quimioterapia, se realizó $A M O$, en la que no se observó células neoplásicas. La evolución clínica y de imágenes a los 12 meses de seguimiento fue satisfactoria.

\section{DISCUSIÓN}

La localización en el hueso del LNH, como sitio primario es inusual (1), y representa menos del $5 \%$ de LNH y menos del 7\% de los tumores óseos primarios $(2,3)$. En nuestro medio no contamos con estudios de prevalencia de esta patología. Se reporta que predomina el sexo masculino (3) y la edad promedio varia entre 36 y 60 años (4). Se describe como predominante en huesos de la mitad inferior del cuerpo (4), ocurriendo cerca del $50 \%$ en huesos largos, principalmente el fémur, mientras que del 25 al 54\% de los casos ocurren a nivel pélvico y vertebral $(5,6)$.

Clínicamente, se manifiesta con dolor en el área ósea afectada y masas palpables (2), fracturas patológicas, compresión de médula espinal (7) y síntomas B (fiebre, 


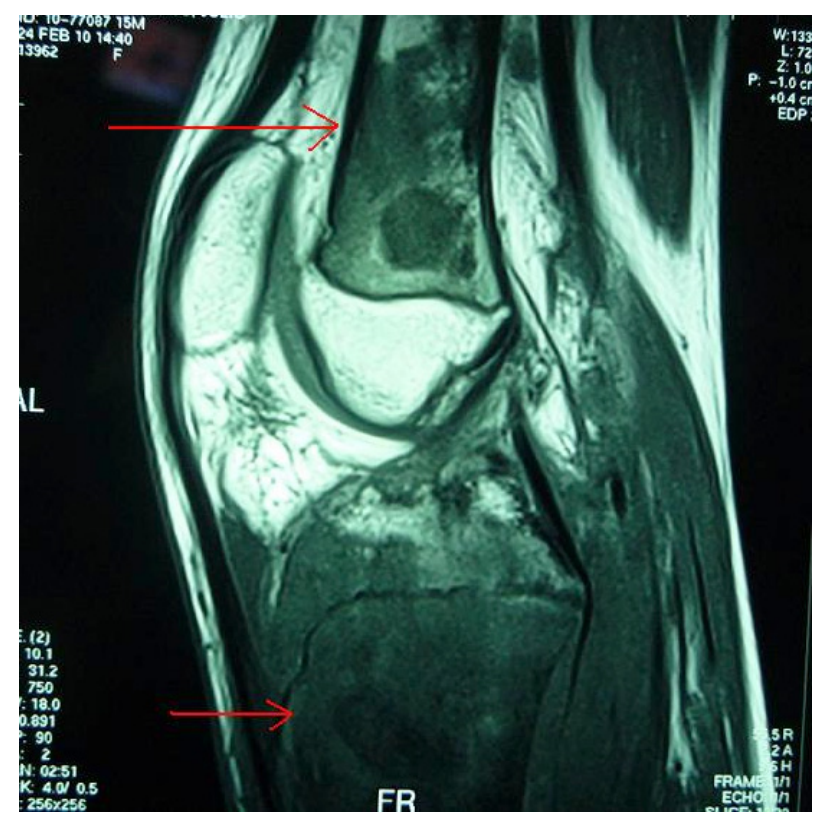

Figura 2. (T1) Se aprecia infiltración tumoral tanto en tibia como a nivel de fémur distal.

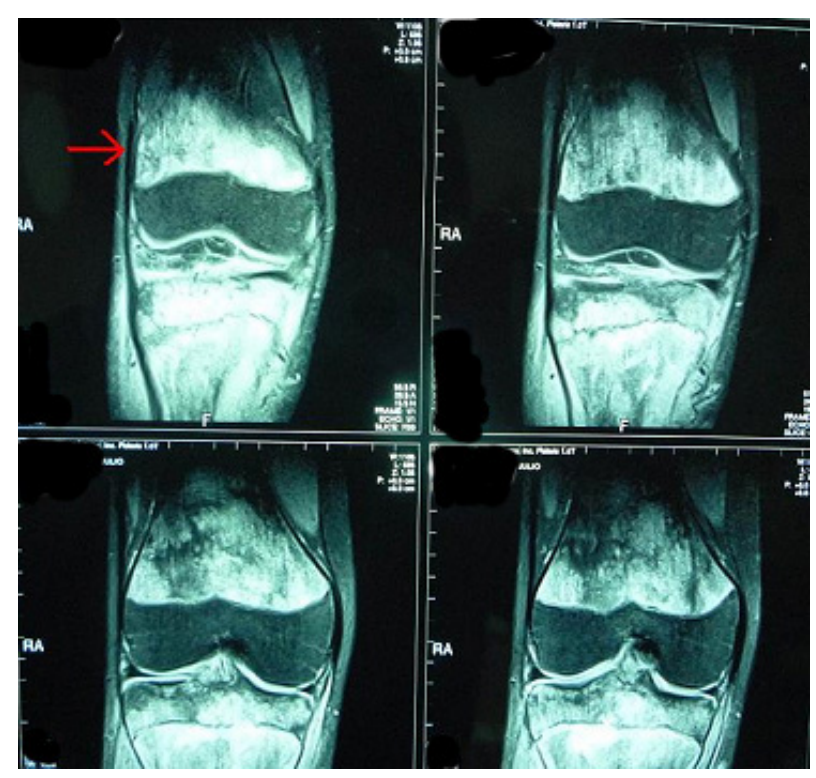

Figura 3. (T2) Infiltración a nivel de tibia proximal y fémur distal, respetando carilla articular.

pérdida de peso)(6,8). Los hallazgos radiológicos son poco específicos pero se describen: lesiones líticas en la parte distal de un hueso largo $(4,8)$ o lesiones destructivas e infiltrativas (9).

Para definir LNH de origen óseo, se deben cumplir los criterios de Coley: 1) Foco primario en un solo hueso. 2) diagnóstico histológico positivo, y 3 ) no evidencia de compromiso de tejido blando o infiltrativo de

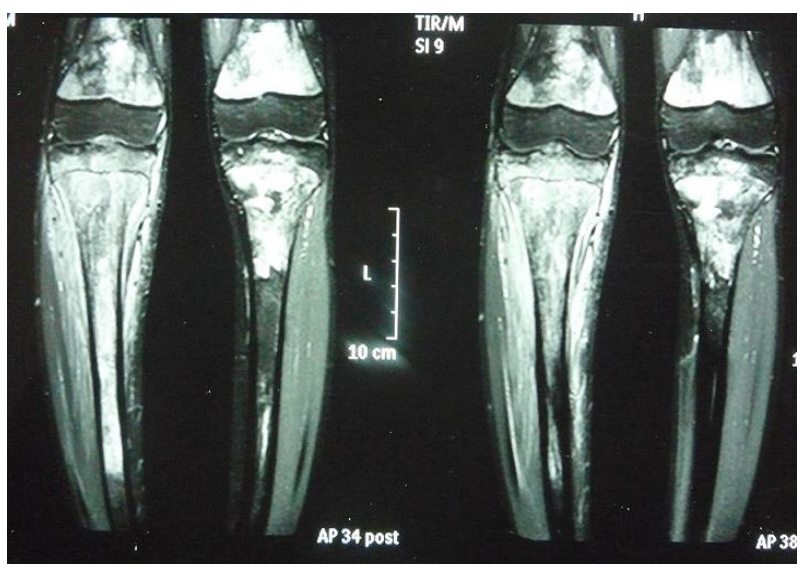

Figura 4. (T1) Se aprecia infiltración tumoral en ambas tibias, a predominio de la derecha.

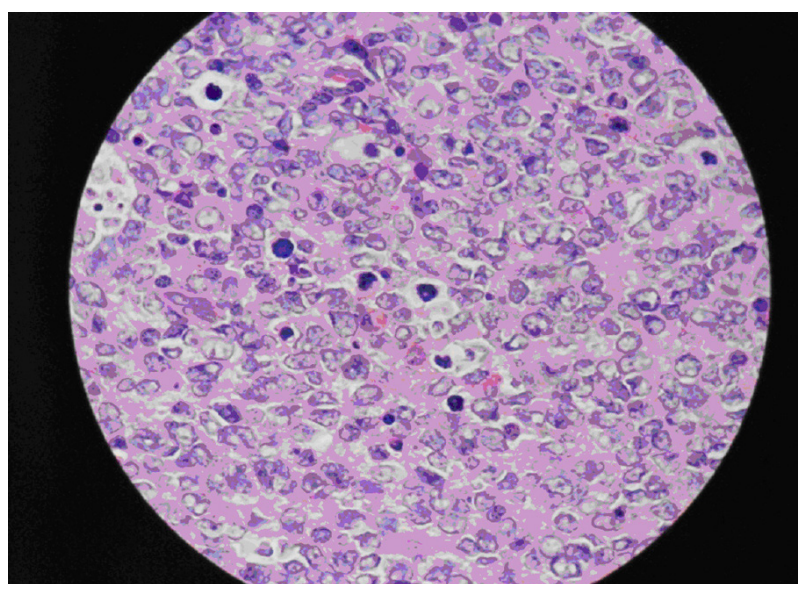

Figura 5. Biopsia ganglionar, Hematoxilina-eosina $(1000 \mathrm{X})$, muestra una arquitectura reemplazada por una proliferación neoplásica de células linfoides de tamaño grande, con núcleos vesiculosos y nucléolo prominente.

Todas las células son neoplásicas y las más oscuras corresponden a figuras de mitosis.

nódulos distantes. El compromiso infiltrativo nodular no es un criterio de exclusión y existen casos donde está comprometido más de un hueso (9). En nuestro paciente no se evidenció otra lesión aparte de la rodilla derecha. A pesar de no haberse realizado biopsia de los segmentos óseos comprometidos, la buena evolución de las lesiones óseas con la quimioterapia apoyó el diagnóstico.

El linfoma difuso de células grandes B es el tipo más común de LNH de presentación ósea $(10,11)$. El tratamiento puede ser con radioterapia, quimioterapia o terapia combinada; reportándose esta última como la de mayor beneficio (12). Recientemente se ha 
encontrado mejora en la sobrevida con el uso de CHOP y rituximab comparados con CHOP $(10,13)$.

En nuestro paciente, las manifestaciones clínicas y las lesiones óseas observadas, siempre fueron sospechosas de lesiones neoplásicas, sin embargo hubo un retardo clamoroso en el diagnóstico. Creemos que, debido al bajo índice de sospecha de este tipo de patologías en población adolescente lleva a hacer diagnósticos basados en la frecuencia, sin tener en cuenta las manifestaciones clínicas ni los hallazgos imagenológicos.

\section{Correspondencia:}

Germán Málaga

Calle Chavín 159 CC Monterrico.

Surco, Lima, Perú.

Correo electrónico: german.malaga@upch.pe

\section{REFERENCIAS BIBLIOGRÁFICAS}

1. Becker S, Babisch J, Venbrocks R, Katencamp D, Wurdinger S. Primary non Hodgkin lymphoma of the spine. Arch Orthop Trauma Surg. 1998; 117(67):339-401.

2. Lones M, Perkins S, Sposto S, et al. Non-Hodgkin's Lymphoma arising in bone in children and adolescents is associated with an excellent outcome: a children's cancer group report. J Clin Oncol. 2002; 20(9): 2293-2301.

3. Smith Z, Sedrak M, Khoo L. Primary bony nonHodgkin lymphoma of the cervical spine: a case report. J Med Case Reports. 2010; 4:35.

4. Baar J, Burkes RL. Primary non-Hodgkin's lymphoma of bone. Semin Oncol. 1999; 26:270275.
5. Horsman J. Primary bone lymphoma: A retrospective analysis. Int J Oncol. 2006; 28:1571-1575.

6. Dai M, Takashi W, Yasuo B, et al. Primary Bone lymphoma: a new and detailed characterization of 28 patients. Jpn J Clin Oncol. 2007; 37(3)216-223.

7. Heyning $\mathrm{FH}$, Hogendoom PC, Kramer MH. Primary non-Hodgkin's lymphoma of bone: a clinicopathological investigation of 60 cases. Leukemia. 1999; 13:2094-98.

8. Mellstedt H. Clinical signs and symptoms at diagnosis and its differential diagnosis. Ann Oncol. 2007; 18: 14-21.

9. Singh T, Satheesh C, Lakshmaiah T, Govind K, Lokanatha D, Linu A. Primary bone lymphoma a report of 2 cases and review of the literature. J Cancer Res Ther. 2010; 6:3.

10. Pinheiro RF, Filho FD, Lim GG, Ferreira FV. Primary non-Hodgkin lymphoma of the bone: an unusual presentation. J Cancer Res Ther 2009; 5 (1):52-3.

11. Brousse C, Baumelou E, Morel P. Primary lymphoma of bone: A prospective study of 28 cases. Joint Bone Spine. 2000; 67: 446-451.

12. Beal K, Allen L, Yahalom J. Primary bone lymphoma: Treatment results and prognostic factors with long-term follow-up of 82 patients. Cancer. 2006; 106:2652-6.

13. Ramadan KM, Shenkier T, Sehn LH, Gascoyne RD. A clinicopathological retrospective study of 131 patients with primary bone lymphoma: A populationbased study of successively treated cohorts from the British Columbia Cancer Agency. Ann Oncol. 2007.8:129-35.

Recibido: 06/04/11

Aceptado para publicación: 19/01/12 